\title{
DDC 23: An Overview
}

by Anne M. Robertson

\author{
Anne Robertson is Vice-chair of the Dewey Decimal \\ Classification (DDC) Editorial Policy Committee (EPC).
}

A $t$ first glance the newest edition of the Dewey decimal classification and relative index (DDC) looks much the same as the edition it supersedes; indeed much of it will be very familiar. However it is very different in some quite significant ways and perhaps some clues to the differences are found in the dedication:

"Dedicated to the worldwide Dewey community."

The aim of all editions has been to keep up with the ever-expanding pace of knowledge, venturing into areas undreamed of in Melvil Dewey's time. This newest edition explicitly acknowledges the vastly expanded range of knowledge and of those who both use the classification and have contributed so generously to the development of

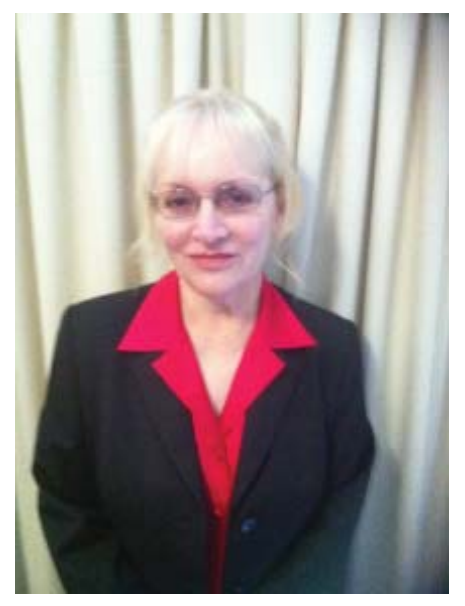
edition 23.

Classifiers familiar with the general principles of using Dewey may be tempted to treat the introductory matter fairly cursorily, and plunge straight into the schedules. This is not a good idea with any edition of the DDC, and it is particularly unwise with edition 23 . While the basic instructions for using the classification remain much the same, there have been many changes, some major, some quite subtle, in the content and structure of this edition.

"Edition 23 includes extensive changes and updates in the terminology used throughout the schedules and tables to improve currency and accessibility for classifiers....The revision process aims to improve the currency of the schedules, whilst continuing to be sensitive to the use of DDC as a shelving tool. Any major changes inevitably bring challenges to libraries not least the costs of relocating and re-labelling stock. To help alleviate these problems, expansion and revision have been preferred to relocation where possible. Significant changes have only been made after careful thought and debate of the relative merits of each action."

Edition 23 is essentially the product of a new approach to how we develop a print edition of the Dewey Decimal Classification. Like Edition 22 it was developed in the context of

1 Caroline Kent, Chair, 2008-Decimal Classification Editorial Policy Committee, "Foreword," in Dewey Decimal Classification and Relative Index, devised by Melvil Dewey, Edition 23, ed. Joan S. Mitchell, Editor in Chief (Dublin, Ohio: OCLC, 2011), xi. 


\section{"This edition}

has a complete

overhaul in the

representation

of groups of

people, important

revisions to a

number of standard

subdivisions,

a considerable

number of updates

throughout

the tables and

schedules, and some

structural changes." the web. But it is the first edition to be developed as a by-product of the underlying database rather than as the sole focus of editorial development. Indeed editorial development has been based on the idea of short-term and long-term updates.

Long-term updates have generally been held back for simultaneous release in both the web and print versions of Edition 23, although the short-term updates have mostly been continuously distributed to users. These have usually been distributed to users using WebDewey, while selected new numbers and changes have been delivered as changes and updates on a monthly basis on the website: www.oclc. org/dewey. All these updates are present in Dewey 23, plus many additional updates.

While the overall aim has been keeping up with the pace of knowledge, which is a paramount goal of all editions, many changes have also been motivated by classifier efficiency and emerging requirements for machine representation and application. These efforts have also been very much informed by interaction with the worldwide community of Dewey users, in addition to consultation with experts in the particular subjects dealt with.

\section{Major Updates}

While the primary focus of this discussion of Edition 23 is to look particularly at changes and developments in the classification of religion (the 200s), like any other part of the classification, this topic is materially affected by changes to the classification as a whole, and to use it effectively an understanding of major updates and changes is necessary.

This edition has a complete overhaul in the representation of groups of people, important revisions to a number of standard subdivisions, a considerable number of updates throughout the tables and schedules, and some structural changes. Many of the structural changes are because over the course of developing this edition a new Editorial Support System, based on the Marc Classification format was introduced, a different underlying data format was adopted, and a new data distribution model was also adopted.

\section{Tables}

How we describe groups of people is a topic frequently reconsidered. As part of developing Edition 23 we looked first at the term "kinds of persons" in the caption at Table $1-08$ and elsewhere throughout the classification, as users are often confused by the differences between "kinds of persons" in Table $1-08$ versus "persons treatment" in Table 1-092: more problematic is the unintended interpretation of "kinds of persons" as a definitive classification of people. To clarify matters somewhat we replaced the phrase with "groups of people" in Table $1--08$ and elsewhere in the Classification. "History and description with respect to" was deleted from the caption both in the Table and elsewhere. "Groups of people" was substituted for "Social groups" 


\section{"There is now}

also a significant

expansion for

collected biography

of groups of

people by various

attributes in Table

1 -092." both in the caption at 305 and elsewhere in the classification.

It has been obvious for a long time that "persons treatment" is a confusing phrase and we questioned whether to continue using it in Table $1-092$. We changed the caption to "Biography", and made a slight revision to the caption at table $1-09$ at the same time. (This caption is now "History, geographic treatment, biography" in place of "Historical, geographic, persons treatment"). There is now also a significant expansion for collected biography of groups of people by various attributes in Table $1-092$.

We have adopted consistent use of the word "people" versus "persons" when referring to a group of people by a specific attribute, although in some cases the term "persons" has been retained when it is part of a common name for a group of people, particularly in a legal context, e.g. "stateless persons". Naturally similar changes have been made in the Relative Index and in addition we have replaced the current "Persons" index with three new entries: Persons (Legal concept), Persons (Individuals), and People. The index term for groups of people in general is "People"; the general index term for individuals is "Persons (Individuals)". We believe these changes will significantly clarify topics relating to "people" and "persons" for classifiers.

\section{Ripple effect}

The small adjustments we have made through Table 1 and 305306 in the developments for groups of people by specific attributes are reflected elsewhere in the classification (the ripple effect), especially in 155 Differential and developmental psychology, 331 Labor economics, and 332 Social problems of and services to groups of people. In a related change we have adjusted the preference order in 302-307 Specific topics in sociology and anthropology to topic first and the group of people second, e.g Friendship in women 302.34082, not 305.4 Women.

\section{Standard Subdivisions}

In addition to those changes there are other significant changes to standard subdivisions in the new edition. Adjustments to specific standard subdivisions are highlighted under Table 1 in the selected list of changes in Edition 23 in Volume 1 Introductory material. There are also several improvements and adjustments in the presentation of standard subdivisions. In records for standard subdivisions that introduce special expansions not found in Table 1, a new note is featured in the record: "Notation ... from Table 1 as modified below". In places where a standard subdivision concept has been displaced to a special provision, we have made sure that an add note appears under the special provision if addition in parallel to the Standard Table 1 provision is desired. We also carefully examined provisions for standard subdivisions in add tables throughout the tables and schedules, and applied the same rules. In Table 1 we realized that 
"We have updated 004-006

\section{Computer science}

(as well as parallel

provisions in

025.04 Information

storage and

retrieval systems

and 621.39

\section{Computer}

engineering) to

reflect current

technical trends.

This in reality is

one of those parts

of the schedules

most likely to be

continually revised

as the classification

strives to keep pace

with the seemingly

non-stop evolution

of devices and

concepts related to

the subjects." the special provisions in the add tables under $-8,--0901-0905$ and -093-099 were incorrectly labelled as "standard subdivisions" in Edition 22. Subsequently we have introduced a note under each noting that the provisions are "special notation," and have added the necessary preference instructions to each of the add tables in Table 1, plus the necessary notes to each entry.

In Table 3B, the notation labelled "Standard subdivisions" in the add table under ---1-8 Specific forms lacked the usual initial 0 and therefore did not look like regular standard subdivisions. We moved the contents of the add table from ---1-8 to ---1 Poetry as explicit subdivisions of the later number, and revised the instructions under the rest of the forms in $-1-8$ to add using the notation following ---100 in ---1001---1009.

\section{Schedules}

We have updated 004-006 Computer science (as well as parallel provisions in 025.04 Information storage and retrieval systems and 621.39 Computer engineering) to reflect current technical trends. This in reality is one of those parts of the schedules most likely to be continually revised as the classification strives to keep pace with the seemingly non-stop evolution of devices and concepts related to the subjects.

In 155 Differential and developmental psychology we have provided for topics of environmental and applied psychology to be applied to groups of people.

A revised and expanded development for logic in 160 Philosophical logic and 511.3 Mathematical logic (Symbolic logic) has been provided.

In 340 Law, we have updated and expanded provisions for the European Union and criminal courts. There is also a parallel expansion for criminal law to match the expansion for criminal offences in 364 Criminology.

Several significant updates have been introduced in 370 Education to generalize provisions from an international perspective with respect to levels of education, kinds of schools, specific subjects in primary education, and policy issues in education. Considering the quite significant differences in educational philosophy, levels and terminology that can be found within states and provinces within one country, let alone separate countries, this has not been a simple task.

Provisions for food and clothing in 390 Customs, etiquette, folklore (and related provisions in 640 Home and family management, 660 Chemical engineering and related technologies and 680 Manufacture of products for specific uses) have also been introduced.

The updates to languages in Table 6 are featured in similar provisions in 400 Language. Throughout 400 Language, addition of Table 2 notation has been regularized for geographic variations of 
"Two changes have been introduced in order to modernise the structure of the classification for machine display and retrieval, and user convenience ... Elimination of dual headings... Elimination of unbalanced spans." languages; special provision is no longer given for the country or countries where use of a language predominates.

As in 400 Language, the updates to languages in Table 6 are reflected in similar provisions in 800 Literature (Belle-lettres) and rhetoric. Minor adjustments have been made to literary period tables throughout 800 , including recasting the notation in the special table for literary periods of Canada under 811-818 Subdivisions for specific forms of American literature in English from standard to optional notation.

You will also find important changes and expansions for topics in the 600s in subjects as different as 610 Medicine and health to the heading at 690 from "Buildings" to "Construction of buildings with expansions for special topics and parts of buildings". Similar changes can be found in 720 Architecture and 721 Architectural materials and structural elements.

Within the 700s you will also find significant updates at 741.5 for Comic books, graphic novels, fotonovelas, cartoons, caricatures and comic strips. 780 Music is another part of the schedules where distinctions among various types of music have been either clarified or eliminated, depending on current attitudes to these types of music.

The changes to geographic areas in Table 2 are reflected in 900 History, geography, and auxiliary disciplines; in addition, historical periods have been updated throughout 900 .

\section{Structural Changes}

Two changes have been introduced in order to modernise the structure of the classification for machine display and retrieval, and user convenience.

Elimination of dual headings:

Dual headings are headings with two distinct terms separated by four hard spaces. In many cases one of the dual headings has been moved to a class-here note.

Elimination of unbalanced spans:

Records for spans in the table and schedules are used to bring together information about a range of numbers or to provide add instructions. Usually the numbers at both ends have the same length, e.g. 810-890, 342-349, 616.1-943.01--.05. This makes it easy to identify which numbers fall underneath the span in the hierarchy. Sometimes, however, the numbers at each end of the span have a different length, e.g., 305.805--.89 Specific ethnic and national groups; this can cause confusion in the print and electronic editions with respect to the position of the span in the hierarchy. Part of the development of Edition 23 has included a review of each unbalanced span. For example, 305.805--.89 has been replaced by two spans, 305.805--.809 and 305.81--.89.

A complete list of relocations, discontinuations, and reused numbers can be found immediately following Tables 1-6 in Volume 1 of Edition 23. 


\section{"Changes to the} classification for

the treatment

of religion are

naturally of

great interest

to theological

collections both

large and small

that are classified

with $D D C$, and

there have been

some quite

interesting and

hopefully useful

developments

within this part of

the Schedules."

\section{Data Representation: behind the scenes}

What you see in the print edition or in WebDewey seems on the surface to be relatively straightforward. It isn't really. Rather like the elegantly effortless grace of a swan as it moves smoothly over water, the energetic paddling hidden beneath, there is rather a lot of effort going on behind the scenes to produce any edition of the DDC.

The print version of Edition 23 was produced using the fourth generation of the Editorial Support System (ESS) introduced in 2010. During the development of Edition 23 the representation of DDC data was migrated from a proprietary format which had been in place since Edition 20 to a new data format based on the Marc 21 formats for Classification and Authority data. When the data is distributed for printing, for inclusion in WebDewey, and to the various translation teams and other users, the data representation is transformed from the internal MARC formats to a MARCXML representation. There are also other representations of DDC data which exist for various other purposes, e.g. SKOS (Simple Knowledge Organization System).

What we as classifiers are familiar with as part of our everyday work is far simpler than the much more complicated underpinnings which produce the end products we use.

\section{The Big Picture}

As you are probably aware, the Dewey Decimal Classification is the most widely used classification throughout the world, and is constantly being translated into yet more languages. Not all translations are used for what I suppose you would call the traditional 'mark and park' function. Neither in fact is it solely used in English speaking countries just for shelf arrangement of traditional physical objects, such as books, journals, prints and photographs, film, video, microfilm, microfiche and so on. It is possible to use it as a classification device for organising knowledge on the Web, and utilising it in much the same way as, for instance, the German National Library, as yet another source for subject access to material by automatically deconstructing the numbers into their meaningful component parts, thereby supplying additional subject access to that derived from more traditional subject thesauri. There is great potential for using classification data as a starting point for developing quite sophisticated subject access services along these lines. Dewey has come a long way since 1876.

\section{Religion}

"Old wine in new bottles, or, changing the emphasis somewhat."

Changes to the classification for the treatment of religion are naturally of great interest to theological collections both large and small that are classified with DDC, and there have been some quite interesting and hopefully useful developments within this part of the Schedules. 
"One of the

\section{late David}

Balatti's wisest

contributions to

the DDC was the

aphorism that

you should 'Never

let an option be

a substitute for a

decision'."
Based as the classification is on the concept of literary warrant, more specifically on what was in Melvil Dewey's library at the time he developed the original version of the classification, it is not surprising that the 200s are perceived as having a markedly Christian bias. Moreover, considering the particular time and place of the original Dewey development, "literary warrant" was likely to lean more towards the $19^{\text {th }}$ century fascination with classical Greek and Roman studies and probably more Protestant in flavour than not.

There is nothing particularly bad or good about this. It is pretty much the norm that a society publishes what is of interest to its members at a particular time, and its library collections will naturally reflect these interests.

Times - and interests - change and for some years now we have been exploring the development of an alternative view of the 200s to reduce the perceived Christian bias in the standard notational sequence for religions in 200. In part, this trend was given added impetus by the Arabic translation team, who wished to be able to give equal emphasis to two or more religions, which was not possible with the schedules as they existed. This was not the only factor involved of course, but it did give rise to some interesting explorations of the topic, as one of the objectives has been to provide adequate space for other religions, and to make better provision for various branches of the Christian churches not particularly well served in the classification as it existed.

As part of the revision process we examined the provision of options in the 200 schedules. One of the late David Balatti's wisest contributions to the DDC was the aphorism that you should "Never let an option be a substitute for a decision". In the course of examining the use made by library classifiers of the Religion schedules, we discovered that not only did remarkably few libraries use any of the 5 possible optional arrangements listed at 290, there were in fact no instructions existing about how to even apply some of them!

Consequently the number of options at 290 has been reduced to two, with the full list of each to be found in the Manual rather than the preferred main schedule numbers.

\section{Eastern Churches}

As part of the revision of the 200 Religion schedules, the numbers for various denominations of the Eastern branches of Christianity were clarified and differentiated as much as possible. This was not always easy for the various specific autocephalous, arbitrary autocephalous, and autonomous, independent churches, but external authorities in this area were consulted and we think the resulting changes are reasonable.

One result of work with the Arabic translation team has been that the schedules for Islam have been further developed and in some cases significantly expanded. The EPC thought it important that the revised numbers for Hadith (Traditions) be published 
"As one means

of exploring

other ways of

treating Religion

the Editorial

Policy Committee

considered The

Universal Decimal

Classification

(UDC) 2 Religion

Schedule, revised

in 2000, which

includes a

chronological/

regional view

of religion that

seemed a promising

model to explore

for an alternative

arrangement in the

$D D C$ not giving a

dominant presence

to any particular

religion." simultaneously in both the print and WebDewey Edition 23. The proposed Schedules were published for public comment, and as far as possible experts in this area were consulted before the revised schedules were published. None of us professes any great expertise in this area but we think the results are as satisfactory as they can be at present, although as always we welcome comments on what does and does not work well.

The needs of the Arabic translation, like any other translation, are not necessarily identical with the main English edition. For instance the Arabic team sees no need for numbers signifying the Koran in literature. The English edition has provision for the Bible in literature, and indeed there is an LC heading Koran in literature, so clearly there is a need for an appropriate number reflecting this in the English edition if not in the Arabic version. "Literary warrant" varies significantly at times in all translations, and some parts of the schedules may be more detailed according to need in those translations, and not necessarily appearing so in the English edition.

\section{Redressing perceptions of bias: future possibilities}

As one means of exploring other ways of treating Religion the Editorial Policy Committee considered The Universal Decimal Classification (UDC) 2 Religion Schedule, revised in 2000, which includes a chronological/regional view of religion that seemed a promising model to explore for an alternative arrangement in the DDC not giving a dominant presence to any particular religion. The Editorial Policy Committee approved further exploration of this concept by the editors to see if such an approach could be fruitfully adapted in some way by the DDC.

\section{NB. The following proposals were not yet officially approved at the time of writing.}

At the top level UDC uses three principles of arrangement:

(1) It generally arranges religions chronologically in order of the foundation of the world's major religions, though the grouping at 25 (Religions of antiquity. Minor cults and religions) doesn't fit well into that pattern.

(2) Secondly, 22/25 are generally arranged by the geographic origins of the religions, with 24 Buddhism being logically part of the group of religions originating in India at 23 , and with $26 / 28$ being a group of religions originating in West Asia (though separated from 252 Religions of Mesopotamia and 253 Other West Asian religions) -- a group called by Muslims Religions of the Book, and sharing the same deity under different names.

(3) A third principle of arrangement is that, generally, religions based on other religions are arranged together. For example, Christianity is next to Judaism, and the Babi and Bahai faiths are next to Islam. 
"Relations between religions is rather a hot topic at present as specialists in the subject working in the Dewey Decimal Section of the Library of Congress have pointed out."
While this arrangement is generally attractive to those in the Dewey world, it is highly doubtful that users would accept the massive relocations that would be required to follow it in the schedules in 220-290.

This arrangement if approved would be referenced by a new note at 220-290:

\section{>220-290 Bible and specific religions}

Option: To provide a chronological/regional arrangement for the Bible and specific religions use the optional arrangement of 220-290 given in appendix $\mathrm{A}^{2}$

Appendix A will be a new part of the 200 Religion separate, and will also be linked in WebDewey, making it easily accessible for cataloguers having access to WebDewey.

When drafting the top-level alternative view of 220-290 in DDC the editors have been strongly influenced by UDC's arrangement. However, editors needed to vary a little from it, particularly with mapping 220 Bible, which UDC provides for at 26-24 (Tanakh. The Hebrew Bible) and at 27-23 (The Bible), but which the DDC wants to continue classifying in one place. Dewey also avoids using the word "primitive" in captions, so would use "Prehistoric religions" as the caption at 201.42. ("Primitive religions" is a Relative Index term at 201.42.)

Probably the most difficult part of the UDC to adapt to the DDC is the section labelled "Religions of antiquity". Apparently in UDC the corresponding $251 / 255$ is organised chronologically, but this sequence looks odd when examined geographically. In DDC it could be arranged geographically by ethnic group, but both Table 2 and Table 5 have their discontinuities here, caused by the way they developed historically in Dewey. Ultimately the arrangement generally follows the current order in Dewey.

A number of other issues, including Religions of the ancient world, Interreligious relations, Divinity and humanity of Christ, Denominations and sects not provided for elsewhere, have been identified as needing further work, and when the proposals are officially approved the resulting changes will be released for general use.

\subsection{Religions of the ancient world}

UDC has a group of religions called "Religions of antiquity": it is proposed to specifically locate them here.

200.93 Religions of the ancient world

Class here religions of antiquity

For Christianity to 325, see 270.1. For a specific religion of antiquity other than Christianity, see the religion in 290, e.g., Classical religion 292, Celtic religion 299.16

2 Giles Martin, Chronological/regional view of 200 Religion (EPC Exhibit 13411.3 May 12, 2011). 
"It is highly likely

that your particular

needs may be not

so unique after

all, and there may

well be a reason for

developments or

changes of a more

universal nature

that can be made to

accommodate your

specific problem:

unless you tell us

we won't know, and

we would prefer

to know so that

as far as possible

the classification

remains relevant

and useful

to as broad a

constituency as

possible."

\subsection{Interreligious relations}

Relations between religions is rather a hot topic at present as specialists in the subject working in the Dewey Decimal Section of the Library of Congress have pointed out. Several religions have numbers for their relations with specific other religions (e.g., 261.22-261.29 Christianity and other religions, 296.396 Judaism and Christianity, 296.397 Judaism and Islam, 297.282 Islam and Judaism, 297.283 Islam and Christianity, 297.284 Islam and religions of Indic origin). Otherwise, there is no provision for showing a specific other religion to which the focal religion is related; it is possible only to show that interreligious relations are involved (e.g., 294.335 Buddhism and interreligious relations). The problem could probably be remedied largely by allowing for the notation for the other religion to be added at 201.5 Interreligious relations, and at the parallel numbers 296.39 and 297.28.

One of the Exhibits presented to the EPC outlines the required changes and additions to the Schedules designed to adequately classify works on this matter. ${ }^{3}$

The majority of these proposed changes, as approved, will form part of the new Religion separate publication when it is published at the end of this year.

\section{Having your say: Dewey and the user's voice}

If you read through the Acknowledgements in Edition 23 you will find a lengthy list of individual names of people who have offered advice on proposed updates, including 200 Religion. Ultimately the continued strength and vitality, the practical usefulness, of the Dewey Decimal Classification depends on its users. Exhibits are made available for comment, for suggested improvements, by anyone who takes an interest in improving classification in all its aspects and who better than the very people who use the Dewey Classification as part of their daily work?

If parts of it don't meet your needs, we encourage you to tell us, preferably before you create specifically local variations in practice. It is highly likely that your particular needs may be not so unique after all, and there may well be a reason for developments or changes of a more universal nature that can be made to accommodate your specific problem: unless you tell us we won't know, and we would prefer to know so that as far as possible the classification remains relevant and useful to as broad a constituency as possible. It continues to remain relevant by the input of its many users and that includes all of you.

Martin, 200 Religion. 


\section{Avenues for further information and contact}

DDC Blog http://ddc.typepad.com/

OCLC http://org/dewey/

ACOC http://www.nla.gov.au/lis/stndrds/grps/acoc/EPCexhibits.html

ACOC Representative robertsonannem@bigpond.com.au

Questions?

dewey@loc.gov (Dewey Editorial Office)

\section{Bibliography}

Dewey, Melvil. Derwey Decimal Classification and Relative Index. Edition 23. Edited by Joan S. Mitchell, Julianne Beall, Rebecca Green, Giles Martin and Michael Panzer. Dublin, Ohio: OCLC, 2011.

Dewey, Melvil. Dewey Decimal Classification. 200 Religion Class. Devised by Melvil Dewey. Edited by Joan S. Mitchell, Julianne Beall...[et al.]; Michael B. Cantlon, decimal classification specialist. Dublin, Ohio: OCLC, 2004.

DDC 23 Workshop. June 7, 2011. Original presentation of this paper used a number of Powerpoint slides originally presented at the noted workshop. While these slides are not directly reproduced here, acknowledgements include Joan S. Mitchell, Julianne Beall, Rebecca Green, Giles Martin, Caroline Kent and Libbie Crawford.

Kent, Caroline, Chair, 2008-Decimal Classification Editorial Policy Committee.

"Foreword." In Dewey decimal classification and relative index. Devised by Melvil Dewey. Edition 23. Edited by Joan S. Mitchell, Editor in Chief, xi. Dublin, Ohio: OCLC, 2011.

Martin, Giles. Chronological/regional view of 200 Religion. EPC Exhibit 134-11.3 May 12, 2011. 